\title{
DEFORMATION MEASUREMENT USING TERRESTRIAL LASER SCANNER FOR CULTURAL HERITAGE
}

\author{
M. O. Selbesoglu a, T. Bakirman ${ }^{\text {a, }}$, O. Gokbayrak ${ }^{\text {b }}$ \\ a Dept. of Geomatic Engineering, Yildiz Technical University, 34220 Esenler Istanbul, Turkey - (oguzs, bakirman)@ yildiz.edu.tr \\ b Governorship of Istanbul, 34110 Fatih Istanbul, Turkey - oguzhangokbayrak@gmail.com
}

Commission II, WG II/2

KEY WORDS: Historical minarets, deformation measurement, cultural heritage, terrestrial laser scanning

\begin{abstract}
:
Historical structures are one of the most essential element of cultural heritage. They reflect history, lifestyle and tradition of a country and society. However, they are damaged through the years due to human activities and natural hazards. Therefore, digital documentation of structures and monuments is critical for preservation, sustainability and protection of cultural heritage. Terrestrial laser scanner is a widespread used tool for obtaining 3D representation of real world. In this study, we aimed to measure deformation of deformed minaret of a historical mosque using terrestrial laser scanner. In order to represent the geometry of the deformed minaret with high accuracy, 31 horizontal sections were created from the transition segment to the spire of the minaret with $30 \mathrm{~cm}$ intervals. The changing curvatures of the minaret were analysed in three parts; cylindrical part, balcony part and upper part. The offsets from the vertical axes for the parts of the minaret were found as $10.14 \mathrm{~cm}, 13.97 \mathrm{~cm}$ and $16.51 \mathrm{~cm}$, respectively.
\end{abstract}

\section{INTRODUCTION}

Cultural heritage symbolically corresponds to the systematic organization of a country or a society and serves as an emblem of culture and tradition (Kim et al., 2010). It also reflects the evolution of the urban expansion, as well as the historical and cultural development of a country (Kutut et al., 2013).

The conservation and protection of historical buildings belonging to the cultural heritage, and preserving their main architectural features are becoming a very sensitive problem due to tourism activities and use of different functions such as residential areas and offices (Ding et al., 2015). The sustainable maintenance, preservation and revitalisation of built cultural heritage, and in particular historic sites, monuments and architectural works, have been in the focus of scientist and researchers (Moropoulou et al., 2013). The preservation and sustainability of built cultural heritage require the use of reliable tools which enable to give a better insight into the complex environment of these structures, by providing an accurate diagnosis of their current conditions, and to identify potential vulnerabilities in order to prevent the risk of damage and to design in advance adequate retrofit solutions (Masciotta et al., 2016). In the past, decisions regarding preservation interventions and protection of monuments were largely based on prior experience, on inadequate and non-systematic identification of the prevailing problems and on available technological resources (Moropoulou et al., 2013). With the latest advances in surveying technology, it is possible to acquire geometrical survey of a complex structure which is very important for both understanding the present state of the structure including its damages and material decays and modelling the structure for the structural analysis (Vatan et al., 2009).

The use of Terrestrial Laser Scanning (TLS) data for deformation measurement is gaining increasing interest in the latest years (Monserrat and Crosetto, 2008). Advantages of using TLS to examine current conditions of structures can be listed as (1) no in situ instrumentation of sensors, (2) no difficulties to reach structures or structural members, (3) independence of natural light sources, and (4) no wiring cost (Park et al., 2007). Pesci et. al. purposed a methodological approach to the TLS-based data processing in order to recognize the deformation patterns of the Garisenda and Asinelli ancient leaning towers in Bologna, Italy (Pesci et al., 2011). Teza and Pesci developed an analysis tool intended for the complete, TLS-based geometric characterization of a cylindrical bell tower whose shape is a deformed and/or leaning (Teza and Pesci, 2013). Pellegrinelli et. al. integrated digital levelling and TLS techniques for geodetic monitoring of ancient leaning bell tower of San Benedetto Church in Ferrara, Italy which is mostly damaged by earthquakes (Pellegrinelli et al., 2014). Leonov et. al. aims to create a precise virtual 3D model of the Shukhov hyperboloid tower in Moscow using laser scanning and the existing documentation and to disseminate the resulting data through the development of suitable visualization software (Leonov et al., 2015). Pesci et. al. use TLS and digital imaging instruments to confirm or deny the little existing historical documentation about the constructive phases of the ancient Palazzo d'Accursio building in Bologna, leading to a reasonable assumption as to its original configuration (Pesci et al., 2012). Lubowiecka et. al. aims to inventory the historical bridges of Galicia, Spain by modelling using TLS, ground penetrating radar and finite element methods in the context of structural dynamics (Lubowiecka et al., 2009). Similarly, Riveiro et. al. researched limit analyses of TLS of masonry arch bridges (Riveiro et al., 2011). Andrés et. al. combined photogrammetry and TLS techniques to obtain 3D model of the great Gate of Antioch in the town of Aleppo, declared a World Heritage Site by UNESCO in 1986, in Syria (Núñez Andrés et al., 2012). Herráez et. al. aims develop a methodology to model the thickness of vaults including not visible parts under the roof in the church of santa maria de magdalena (Valencia, Spain) with TLS techniques for structural restoring (Herráez et al.,

* Corresponding Author 
2014). Tapete et. al. integrated Ground-Based Synthetic Aperture Radar Interferometry and TLS to obtain 3D interferometric radar point clouds to facilitate the spatial interpretation of displacements affecting archaeological monuments in the central archaeological area of Rome (Tapete et al., 2013). There are also various studies that take advantage of TLS on documentation, monitoring and modelling archaeological sites such as Umayyad, Jordan (Al-kheder et al., 2009), Pinchango Alto, Peru (Lambers et al., 2007) and Pinara, Turkey (Hinzen et al., 2013).

In this study, we aimed to measure deformations of minaret of a 386 year old historical mosque using terrestrial laser scanner. The basic elements of a minaret are: footing, boot (kaide), transition segment (küp), cylindrical or polygonal body shaft, balcony (şerefe), upper part of the minaret body (petek), spire/cap (külah) and end ornament (alem) (Figure 1). Inclination and other parameters of the minaret are calculated by horizontal sections created using the point cloud derived from the scans. In order to present curvature and deformations precisely based on point cloud data derived from TLS, horizontal sections with $30 \mathrm{~cm}$ intervals are created.

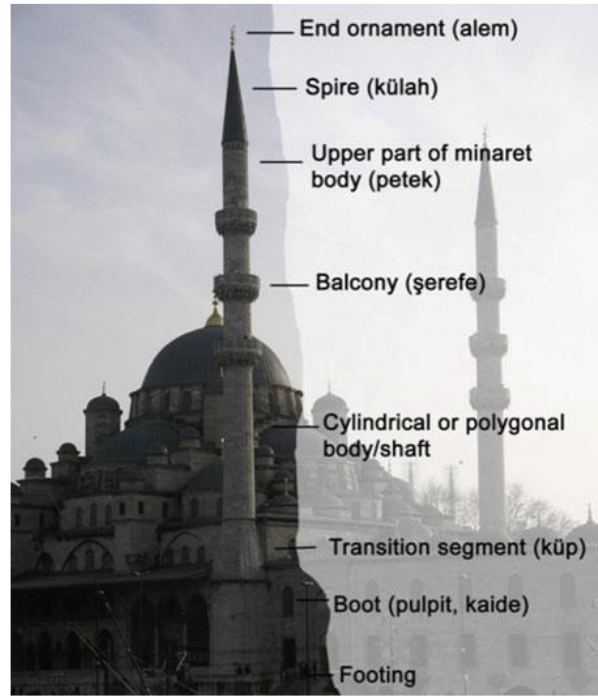

Figure 1. Elements of a minaret (Pellegrinelli et al., 2014)

\section{STUDY AREA}

Our study area is historical Haci Piri Mosque minaret located in Beyoglu, Istanbul which was built in 1630 as an Islamic monastery with the name of Kadirihane Tekkesi (Figure 2). The monastery has been restored and renovated several times through centuries. A water fountain has been built by the mother of Sultan Mahmud I in 1732 and another fountain has been built inside the mosque in 1764. It was almost destroyed twice by fire and restored by Sultan Mustafa III and Sultan Mahmud II in 1765 and 1823, respectively. Latest renovations were carried out by Sultan Abdulhamid II by restoring some parts of the monastery and adding some new units in 1895 . After prohibition of Islamic monasteries in 1925, it has been used as a mosque. In 1997, another fire has destroyed some units and the mosque has been damaged (Pesci et al., 2011). Current state and a section of the minaret can be seen in Figure 3 and Figure 4, respectively. Minaret's tilt can be distinguished just by eye observation so documentation and deformation processes of the structure is vital.

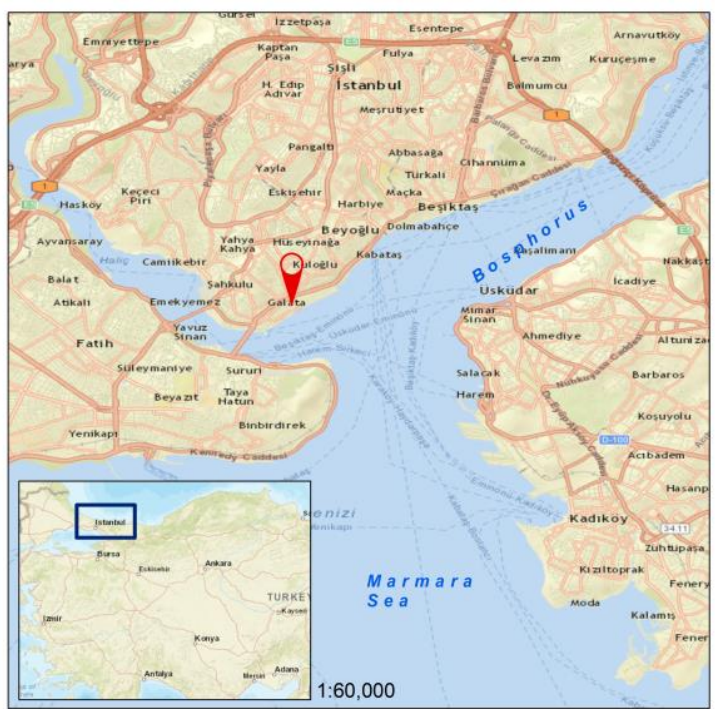

Figure 2. Study area

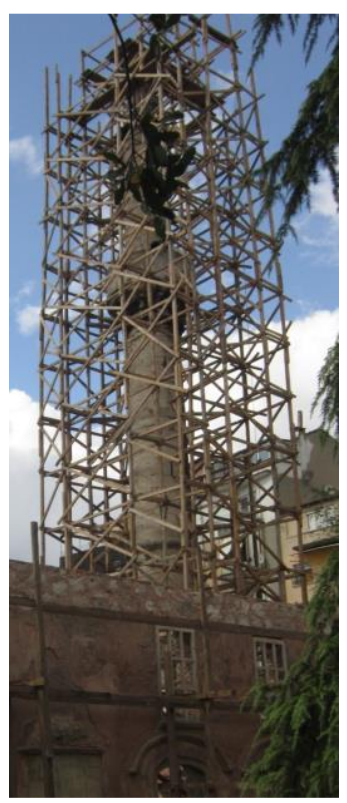

Figure 3. View of minaret

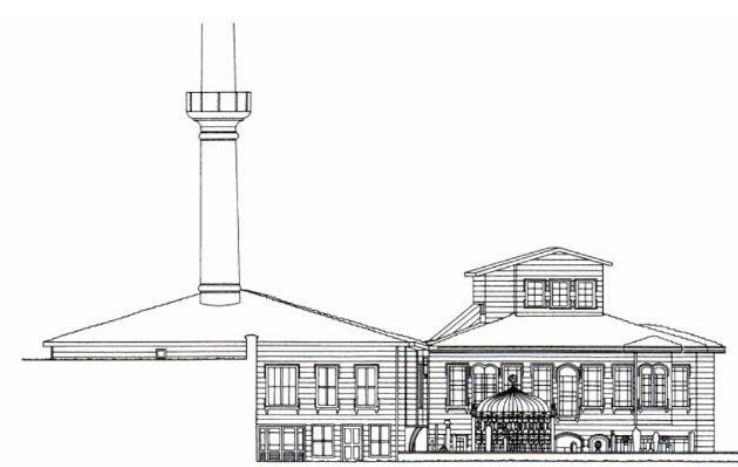

은:2:3.4. $3 m$

Figure 4. Front view of the mosque and cemetery (Teza and Pesci, 2013) 


\section{METHODOLOGY}

The purpose of the study is determining the deformations of the Hac1 Piri mosque minaret on the vertical axis using TLS technology. The structure has scaffold to prevent the collapse of the minaret and horizontal and vertical connections to the components of the scaffold elements constitute difficulties to be measured by other methods such as total station. Therefore, laser scanner technology was used in order to generate the $3 \mathrm{~d}$ representation of the minaret. In addition, in order to restore the deformed minaret based on restoration project, the relief of the minaret including the position of centre of gravity were determined using TLS observations. TLS point density is higher than the traditional measurement techniques based on angle and distance measurements acquired by Total station. For instance, especially in architectural applications, the definition of the vertical plane is important. Trimble GX 200 provides accurate information regarding with vertical axis of the structures based on vertical dual axis compensator that allows the accurate levelling of the instrument. The specifications of the Trimble GX 200 are shown in Table 1.

Table 1. Technical specifications of terrestrial laser scanner:

\begin{tabular}{|c|c|}
\hline \multicolumn{2}{|r|}{ Trimble GX 200} \\
\hline Range & standard: $200 \mathrm{~m}$; extended: $350 \mathrm{~m}$ \\
\hline Scanning speed & up to 5000 points per second \\
\hline Standard deviation: & $\begin{array}{l}1.4 \mathrm{~mm} @ \leq 50 \mathrm{~m}: 2.5 \mathrm{~mm} @ 100 \mathrm{~m} \\
3.6 \mathrm{~mm} @ 150 \mathrm{~m}: 6.5 \mathrm{~mm} @ 200 \mathrm{~m}\end{array}$ \\
\hline $\begin{array}{l}\text { Single point } \\
\text { accuracy }\end{array}$ & $\begin{array}{l}\text { position=12 mm @ } 100 \mathrm{~m}: \\
\text { distance=7 mm @100 m }\end{array}$ \\
\hline Hz angle & $12^{\prime \prime}(60 \mu \mathrm{rad}):$ Vt angle $=14^{\prime \prime}(70 \mu \mathrm{rad})$ \\
\hline Target acquisition & std dev. $<1 \mathrm{~mm}$ (Trimble targets) \\
\hline $\begin{array}{l}\text { Modelled surface } \\
\text { precision }\end{array}$ & $\pm 2 \mathrm{~mm}$ (depending on method) \\
\hline Levelling & circular level in tribrach: $8^{\prime}$ \\
\hline $\begin{array}{l}\text { Electronic dual } \\
\text { axis level: }\end{array}$ & resolution $6^{\prime \prime}$, range: $\pm 14^{\prime}$ \\
\hline Scan resolution & spot size: $3 \mathrm{~mm} @ 50 \mathrm{~m}$ \\
\hline $\begin{array}{l}\text { Spot size with } \\
\text { autofocus: }\end{array}$ & $\begin{array}{c}0.3 \mathrm{~mm} @ 5 \mathrm{~m} ; 0.9 \mathrm{~mm} @ 15 \mathrm{~m} ; \\
1.5 \mathrm{~mm} @ 25 \mathrm{~m}\end{array}$ \\
\hline Scan row $(\mathrm{hz})$ & $\begin{array}{c}200,000 \text { points } \\
\text { Scan row }(v t): 65,536 \text { points }\end{array}$ \\
\hline
\end{tabular}

TLS measurements and processes were carried out in three steps. First step is measurement of ground control points by total station (geodetic survey), second step is geo-referencing of scanned point clouds and last step is the creating of the sections regarding with the footing, boot (kaide), transition segment (küp), cylindrical or polygonal body shaft, balcony (şerefe), upper part of the minaret body (petek), spire/cap (külah) and end ornament (alem).

\section{RESULTS AND DISCUSSION}

Firstly, corner points of the boot of minaret were measured using $1+1 \mathrm{ppm}$ precise Total Station. Elevations of corner points were found between differences of 1 millimetre to 1.7 millimetre. This results demonstrate that the vertical axis offsets are not caused by the boot part of the minaret. To determine the location of measurement sessions, exploratory study was carried out at the site and it was decided that it would be optimal to be scanned from three different points with the laser scanner (Figure 5). The Hacı Piri mosque was scanned by Trimble GX 200 laser scanner from approximately 40 meter with $5 \mathrm{~mm}$ point density. Then, registration process of the three different point clouds was carried out by using the Real Works software. In order to determine the geometry of the deformed minaret, 31 horizontal sections were created from the transition segment to the spire of the minaret (Figure 6). 20 sections were created between the transition segment to the balcony and the remainder 11 sections were created between the balcony and the spire of the minaret. The distance between sections are determined as 30 $\mathrm{cm}$.

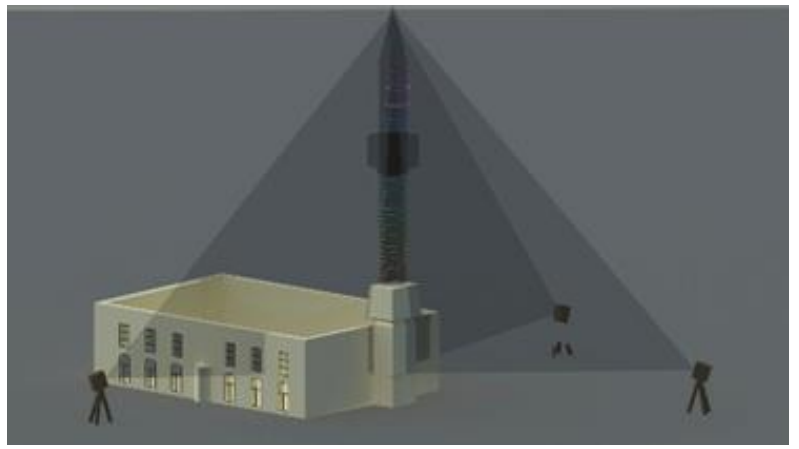

Figure 5. The scanning geometry from three points.

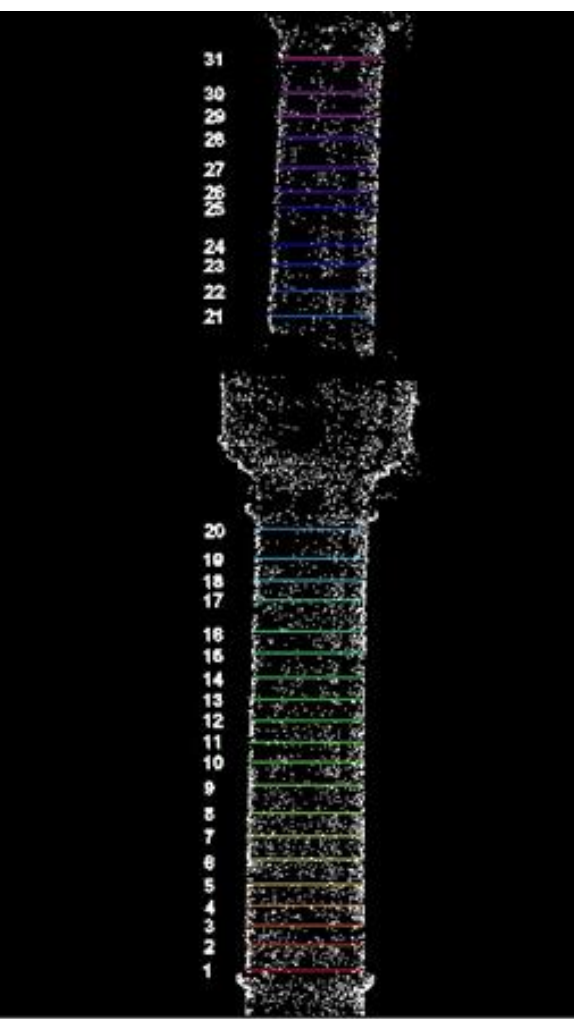

Figure 6. Sections of the minaret obtained through point cloud 
Subsequently, 1st section belonging to transition segment was taken as reference circle and evaluations regarding with determination the curvature of minaret were based on this reference section. The centre of the circle of section 1 , as shown in the Figure $7 \mathrm{a}$, forming the vertical direction and the difference with the centre of the circle forming the number 20 section under the balcony was measured. Difference between these two circles' centres was found to be $10.14 \mathrm{~cm}$ (Figure 7a).

Then, the difference between the centres of circles of $21 \mathrm{st}$ section above the balcony and the 31 st section at the spire was found to be $16.51 \mathrm{~cm}$ (Figure 7b).

The difference between the centre of circles at the top and bottom of balcony (sections 20 and 21) was found $13.97 \mathrm{~cm}$ as shown in Figure 8.

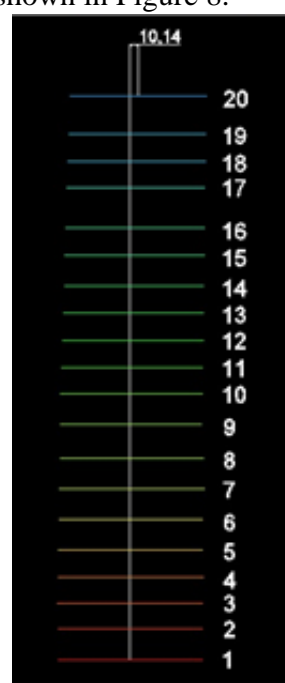

(a)

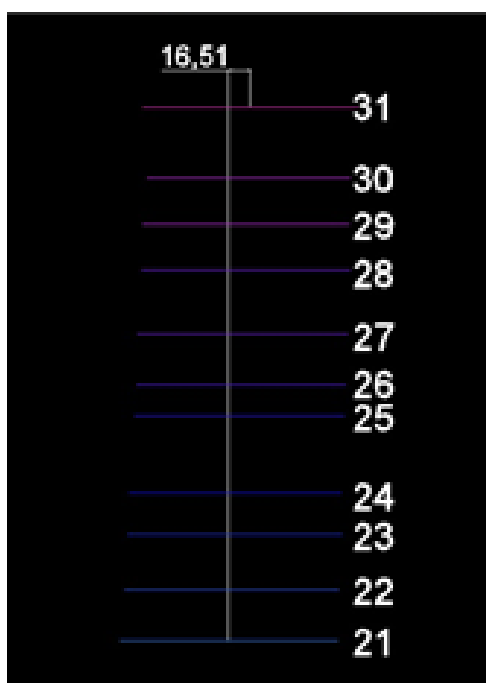

(b)
Figure 7. (a) Sections of the minaret from transition segment to balcony, (b) Sections of the minaret from balcony to spire

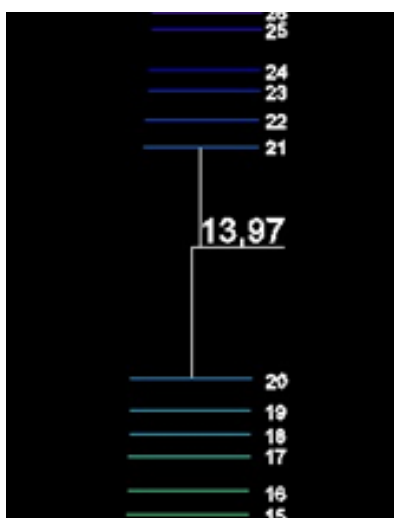

Figure 8. Deviations in the vertical direction from top to bottom of balcony.

$40.63 \mathrm{~cm}$ difference was determined between the centre of gravity of the circle with the section 31 and section 1 , when deformation of the whole minaret is analysed. These differences can be seen for plan and front view for whole minaret in Figure 9.

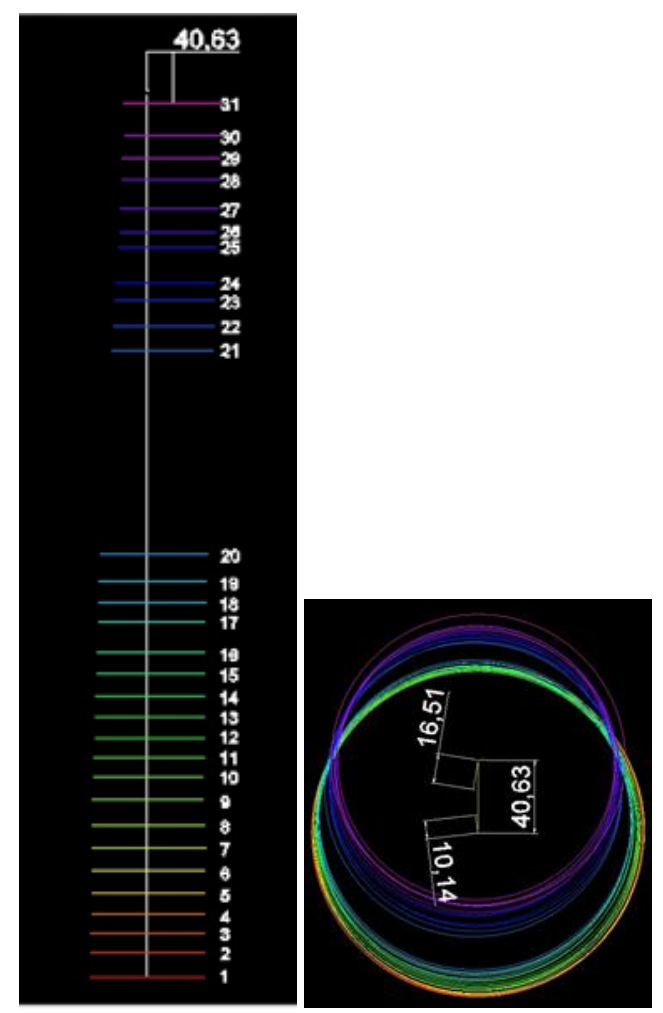

Figure 9. Deviations in the vertical direction for whole minaret.

\section{CONCLUSIONS}

The proposed analysis demonstrate that the deformation of the historical structures can be determined in high precision since the density of TLS measurements when compared to the traditional methods such as geodetic surveys. TLS technology can be used not only for deformation monitoring of historical structures but also for documentation of cultural heritage and recording of archaeological remains.

Laser scanning technology provides density point cloud data which facilitate the digital reconstruction and generate $3 \mathrm{~d}$ realistic models. It is widely used in many areas and is an effective way for deformation monitoring of structures, especially in the preservation of historical structures. Monitoring and digital documentation of historic structures that deform through time is of great importance in order to prevent and forward cultural heritage to the future generation of human imperative. For this purpose, deformation of the historical minaret of the Hac1 Piri mosque Islamic monastery was evaluated using laser scanner technology. The sections were created from the point cloud to determine the actual geometry of the minaret with high accuracy. Results demonstrate that the deformation on the vertical plane of the minaret is $40.63 \mathrm{~cm}$. Consequently, the intense data obtained from laser scanner allows us to present the deformation with high accuracy for each element of minarets. As a follow up step of this research, we are also considering the investigation and extensive analysis of some parameters such as scanning interval, distance from the scanning object to the device, shape, structure, volume, roughness and density of point cloud that could extremely affect the quality of deformation analysis.

In the future studies, we would like to incorporate with photogrammetric methods as well as geodetic techniques that could provide us to compare the methods aforementioned. Furthermore, we are also planning to test the laser scanning 
technology for analysing the landslides and the deformations are caused by natural hazards.

\section{ACKNOWLEDGEMENTS}

Authors would like to thank to Architect Bora Cenk Okumus from Governorship of Istanbul and Architect Mehmet Guler from Arma Project and Restoration Inc. for their support and providing required instruments for the study.

\section{REFERENCES}

Al-kheder, S., Al-shawabkeh, Y., Haala, N., 2009. Developing a documentation system for desert palaces in Jordan using 3D laser scanning and digital photogrammetry. Journal of Archaeological Science 36, 537-546.

Ding, L., Wu, X., Zhang, L., Skibniewski, M.J., 2015. How to protect historical buildings against tunnel-induced damage: A case study in China. Journal of Cultural Heritage 16, 904-911.

Herráez, J., Navarro, P., Denia, J.L., Martín, M.T., Rodríguez, J., 2014. Modeling the thickness of vaults in the church of santa maria de magdalena (Valencia, Spain) with laser scanning techniques. Journal of Cultural Heritage 15, 679-686.

Hinzen, K.-G., Schreiber, S., Rosellen, S., 2013. A high resolution laser scanning model of the Roman theater in Pinara, Turkey - comparison to previous measurements and search for the causes of damage. Journal of Cultural Heritage 14, 424-430.

Kim, C.-J., Yoo, W.S., Lee, U.-K., Song, K.-J., Kang, K.-I., Cho, H., 2010. An experience curve-based decision support model for prioritizing restoration needs of cultural heritage. Journal of Cultural Heritage 11, 430-437.

Kutut, V., Zavadskas, E.K., Lazauskas, M., 2013. Assessment of Priority Options for Preservation of Historic City Centre Buildings using MCDM (ARAS). Procedia Engineering 57, 657-661.

Lambers, K., Eisenbeiss, H., Sauerbier, M., Kupferschmidt, D., Gaisecker, T., Sotoodeh, S., Hanusch, T., 2007. Combining photogrammetry and laser scanning for the recording and modelling of the Late Intermediate Period site of Pinchango Alto, Palpa, Peru. Journal of Archaeological Science 34, 17021712 .

Leonov, A.V., Anikushkin, M.N., Ivanov, A.V., Ovcharov, S.V., Bobkov, A.E., Baturin, Y.M., 2015. Laser scanning and 3D modeling of the Shukhov hyperboloid tower in Moscow. Journal of Cultural Heritage 16, 551-559.

Lubowiecka, I., Armesto, J., Arias, P., Lorenzo, H., 2009. Historic bridge modelling using laser scanning, ground penetrating radar and finite element methods in the context of structural dynamics. Engineering Structures 31, 2667-2676.

Masciotta, M.-G., Roque, J.C.A., Ramos, L.F., Lourenço, P.B., 2016. A multidisciplinary approach to assess the health state of heritage structures: The case study of the Church of Monastery of Jerónimos in Lisbon. Constr Build Mater 116, 169-187.

Monserrat, O., Crosetto, M., 2008. Deformation measurement using terrestrial laser scanning data and least squares 3D surface matching. ISPRS Journal of Photogrammetry and Remote Sensing 63, 142-154.

Moropoulou, A., Labropoulos, K.C., Delegou, E.T., Karoglou, M., Bakolas, A., 2013. Non-destructive techniques as a tool for the protection of built cultural heritage. Constr Build Mater 48, 1222-1239.

Núñez Andrés, A., Buill Pozuelo, F., Regot Marimón, J., de Mesa Gisbert, A., 2012. Generation of virtual models of cultural heritage. Journal of Cultural Heritage 13, 103-106.

Park, H.S., Lee, H.M., Adeli, H., Lee, I., 2007. A New Approach for Health Monitoring of Structures: Terrestrial Laser Scanning. Computer-Aided Civil and Infrastructure Engineering 22, $19-30$

Pellegrinelli, A., Furini, A., Russo, P., 2014. Earthquakes and ancient leaning towers: Geodetic monitoring of the bell tower of San Benedetto Church in Ferrara (Italy). Journal of Cultural Heritage 15, 687-691.

Pesci, A., Bonali, E., Galli, C., Boschi, E., 2012. Laser scanning and digital imaging for the investigation of an ancient building: Palazzo d'Accursio study case (Bologna, Italy). Journal of Cultural Heritage 13, 215-220.

Pesci, A., Casula, G., Boschi, E., 2011. Laser scanning the Garisenda and Asinelli towers in Bologna (Italy): Detailed deformation patterns of two ancient leaning buildings. Journal of Cultural Heritage 12, 117-127.

Riveiro, B., Morer, P., Arias, P., de Arteaga, I., 2011. Terrestrial laser scanning and limit analysis of masonry arch bridges. Constr Build Mater 25, 1726-1735.

Tapete, D., Casagli, N., Luzi, G., Fanti, R., Gigli, G., Leva, D., 2013. Integrating radar and laser-based remote sensing techniques for monitoring structural deformation of archaeological monuments. Journal of Archaeological Science 40, 176-189.

Teza, G., Pesci, A., 2013. Geometric characterization of a cylinder-shaped structure from laser scanner data: Development of an analysis tool and its use on a leaning bell tower. Journal of Cultural Heritage 14, 411-423.

Vatan, M., Selbesoglu, M.O., Bayram, B., 2009. The use of 3D laser scanning technology in preservation of historical structures. Wiadomości Konserwatorskie, 659-669. 